\title{
Caesarean scar pregnancy: a case report with review of management options
}

\section{Vandana Rani*, Shaveta Jain, Vani Malhotra, Meenakshi B. Chauhan, Sarika Gautam, Smiti Nanda, Neetu Sangwan}

Department of Obstetrics and Gynaecology, Pt B. D. S, PGIMS, Rohtak, Haryana, India

Received: 18 August 2019

Accepted: 30 September 2019

\section{*Correspondence:}

Dr. Vandana Rani,

E-mail: drvandana882@gmail.com

Copyright: (c) the author(s), publisher and licensee Medip Academy. This is an open-access article distributed under the terms of the Creative Commons Attribution Non-Commercial License, which permits unrestricted non-commercial use, distribution, and reproduction in any medium, provided the original work is properly cited.

\begin{abstract}
Cesarean scar pregnancy is a rare but life-threatening complication. It is the abnormal implantation of gestational sac into myometrium and fibrous scar of previous cesarean section. Its incidence is on rising trend due to increase in rate of cesarean section all over the world. A thirty years old second gravida presented at eight weeks of gestation with complaints of bleeding per vaginum and pain lower abdomen. She was diagnosed as a case of cesarean scar pregnancy (CSP) on ultrasonography and confirmation of diagnosis was done on magnetic resonance imaging. Medical management of scar pregnancy was done successfully with combination of mifepristone and methotrexate. Cesarean scar pregnancy could be catastrophic, if not managed well in time. Management includes both surgical and medical options. Treatment has to be individualized depending on patient's hemodynamic profile, size of gestational sac, desire for future fertility, compliance for follow up and availability of interventional radiology.
\end{abstract}

Keywords: Cesarean scar pregnancy, Cesarean section, Ectopic, Methotrexate, Mifepristone, Serum $\beta$-hCG

\section{INTRODUCTION}

Implantation of a pregnancy within the scar of a previous caesarean delivery is the rarest form of ectopic pregnancy. Incidence of caesarean scar pregnancy (CSP) ranges from 1:1800 to 1:2216, which represents $6.15 \%$ of all ectopic pregnancies in women with a prior caesarean delivery. ${ }^{1,2}$ A greater number of cases of caesarean scar pregnancies are currently being reported as the rates of caesarean sections are increasing globally and as detection of scar pregnancy has improved with use of trans-vaginal ultrasound with color Doppler imaging.

We reported a case of caesarean scar pregnancy (CSP) which was successfully treated by combination of mifepristone and methotrexate. Various other management options for scar pregnancy in the literature are also discussed.

\section{CASE REPORT}

A 30-year-old, second gravida at period of gestation eight weeks, presented to the emergency department of Obstetrics and Gynaecology with complaints of bleeding per vaginum and pain lower abdomen for last two days. She had history of one caesarean delivery for breech presentation four years back. On examination, she was hemodynamically stable. There was no pallor. On Per abdomen examination, abdomen was soft and non-tender. Per speculum examination revealed closed cervical os and no bleeding was observed. The size of uterus was corresponding to the period of gestation and there was no tenderness in any of the fornices. Trans-vaginal 
ultrasound scan revealed a gestational sac implanted at the level of previous caesarean scar extending into scar region with thinning of anterior uterine wall. Fetal pole is also seen within the sac (Figure 1). Color Doppler showed increased trophoblastic flow around sac and within the fetal pole suggestive of live scar pregnancy (Figure 2). Magnetic resonance imaging was done which confirmed the ultrasound findings and a diagnosis of viable caesarean scar pregnancy was made. Serum $\beta$ human chorionic gonadotrophin ( $\beta$-hCG) level was 48150 $\mathrm{IU} / \mathrm{ml}$. After proper counselling regarding the conservative management and compliance for longer follow-up, decision for medical management was taken. A single dose of Injection methotrexate $(50 \mathrm{mg}$ ) was given by intra-muscular route. On the seventh day after methotrexate injection, fetal cardiac activity was still present on trans-vaginal ultra-sound scan and serum $\beta$ hCG levels were $45,500 \mathrm{IU} / \mathrm{ml}$. Failure of response to the systemic methotrexate therapy was considered and combination of mifepristone and local intra-gestational with systemic methotrexate was opted. Tablet mifepristone $200 \mathrm{mg}$ stat was given per orally on day 9 . Mifepristone is an antiprogesterone drug and helps to destroy and detach the chorionic villi thus, making methotrexate more effective. Injection methotrexate $(25$ $\mathrm{mg}$ ) was given locally into the sac under ultrasound guidance and $25 \mathrm{mg}$ Injection methotrexate was given by intra-muscular route on the next day. On day 13, transvaginal ultra-sound scan was repeated which revealed absence of cardiac activity and serum $\beta$-hCG levels were $2600 \mathrm{IU} / \mathrm{ml}$. Also, there was decrease in crown-rump length of fetus. Serum $\beta$-hCG levels decreased to 93.3 $\mathrm{IU} / \mathrm{ml}$ on day 24 and $3.3 \mathrm{IU} / \mathrm{ml}$ on day 66 . There was complete absorption of the sac revealed by trans-vaginal scan on day 90.

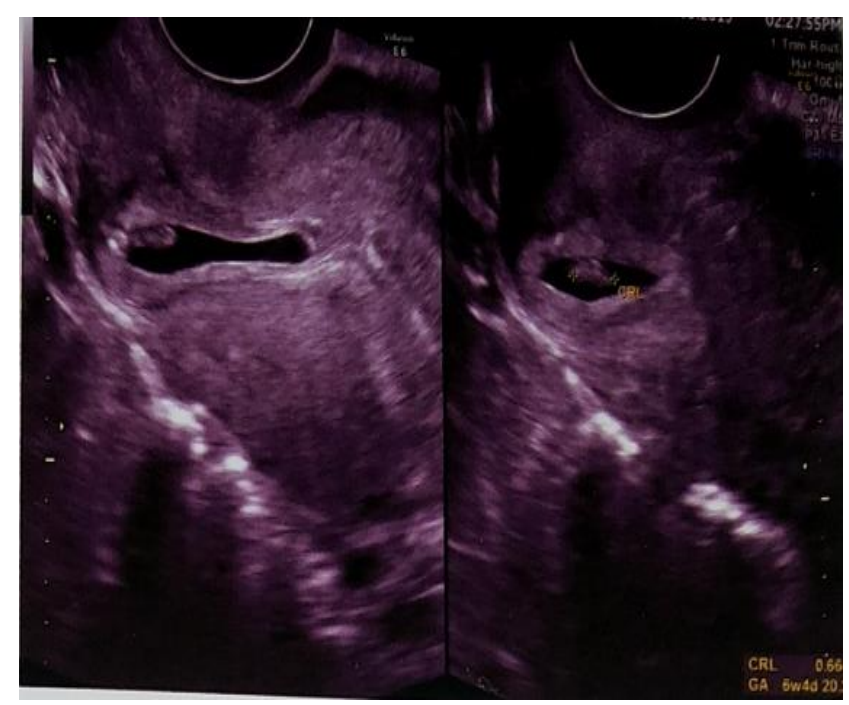

Figure 1: Cesarean scar pregnancy.

\section{DISCUSSION}

A caesarean scar pregnancy is a rare condition. The first case was reported in 1978 by Larsen and Solomon. ${ }^{3}$ Since then, the incidence of caesarean scar pregnancy is on rise due to global increase in number of caesarean sections and increased availability of diagnostic methods.

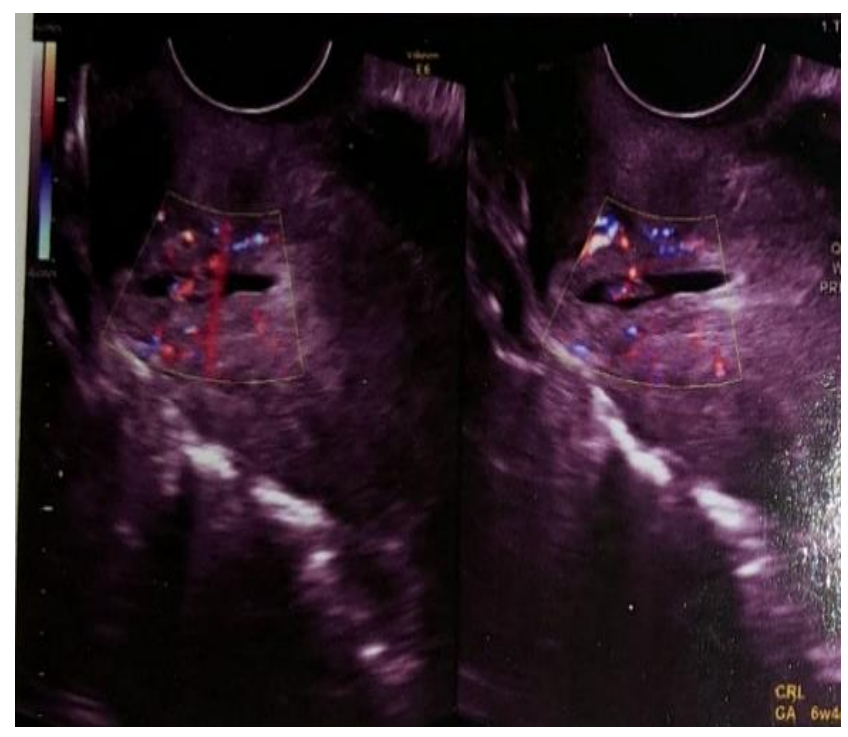

Figure 2: Doppler picture of scar pregnancy showing increased flow.

The most probable mechanism through which this can occur is the invasion of the myometrium through a microscopic tract. The tract is believed to develop from trauma from previous uterine surgeries like dilatation and curettage, myomectomy, metroplasty and caesarean section. - $6^{-6}$ Though it is the rarest, but high index of suspicion should be kept in mind in patients with risk factors. If gestational sac is found at the level of uterine isthmus in a patient with previous caesarean section, possibility of caesarean scar pregnancy should be considered. Trans-vaginal ultrasonography combined with doppler is a reliable tool for diagnosing caesarean scar pregnancy. Ultrasound imaging criteria to diagnose caesarean scar pregnancy are- empty uterine cavity and cervical canal, development of gestational sac in the anterior uterine wall at the isthmus, evidence of functional trophoblastic circulation on doppler examination, defined by the presence of an increased peri-trophoblastic vascularity on color doppler examination and absence of healthy myometrium between the bladder and the sac, allowing differentiation from cervico-isthmic implantation. ${ }^{6,7}$ Trans-vaginal ultrasonography has a sensitivity of $84.6 \%$ for diagnosis of caesarean scar pregnancy. ${ }^{8}$ There is no standard treatment for caesarean scar pregnancies. Termination of pregnancy is recommended soon after confirmation of caesarean scar pregnancy to avoid catastrophic complications such as uterine rupture and heavy bleeding. Proposed interventions for CSPs include Methotrexate alone or in conjunction with bilateral uterine artery embolization (UAE), dilation and curettage (D and C) after UAE, regular D and C alone, hysteroscopy, laparoscopy, laparotomy or hysterectomy. ${ }^{1,9}$ 
Treatment is individualized according to hemodynamic stability of the patient, size of gestational sac and desire for future fertility. Our patient was hemodynamically stable, and she was second gravida with only one living child, so, considering her desire for future fertility, medical management with mifepristone and methotrexate (systemic and local) was considered. Our management was unique in a way that we used mifepristone and a combination of both systemic and local injection of methotrexate into the sac, which had not been previously used in the literature.

Combination of mifepristone and methotrexate had been previously used by Srinivas $M$ and Shan-rung Shu et al successfully. ${ }^{10,11}$ Srinivas $M$ et al used the combination of mifepristone and systemic methotrexate and Shan-rung Shu et al treated their case of CSP by curettage and aspiration guided by laparoscopy after systemic methotrexate injection accompanied with mifepristone.

Another case series showed use of mifepristone, but it was subsequent to embryocide and mifepristone was used 12 hourly for three days. ${ }^{12}$

Godin et al, successfully treated a case of CSP by transvaginal ultra-sound guided injection of methotrexate after aspiration of sac contents. ${ }^{8}$ It seems logical that the caesarean scar pregnancy, being surrounded by fibrous scar rather than normally vascularized myometrium, would have limited systemic access. Thus, direct injection of methotrexate into the sac would probably be more effective.

In our patient, systemic methotrexate was given initially as the patient was hemodynamically stable with no contraindication to methotrexate. Nevertheless, due to failure of systemic methotrexate, mifepristone was given and subsequently, intra-sac injection of methotrexate was given under ultra-sound guidance. A drop of $15 \%$ at an interval of one week is expected with methotrexate treatment. In our case, there was only $5.5 \%$ decrease in Serum $\beta$-hCG level. So, Tablet mifepristone $200 \mathrm{mg}$ stat was given per orally on day 9 . Injection methotrexate (25 $\mathrm{mg}$ ) was given locally into the sac under ultrasound guidance and $25 \mathrm{mg}$ Injection methotrexate was given by intra-muscular route on the next day. There was $94.3 \%$ fall in Serum $\beta$-hCG level on day 13. On follow-up by serial Serum $\beta$-hCG level, it decreased gradually and became $3.3 \mathrm{IU} / \mathrm{ml}$ on day 66 .

Timor and Tritch et al, recommended the combination of systemic and intra-gestational sac administration of methotrexate in their case series. ${ }^{9}$ Jurkovic et al, recommended the combination therapy of methotrexate treatment with local injection of potassium chloride in cases of detectable embryonic cardiac activity. ${ }^{7}$

Fadhlaoui et al, reported a case of caesarean scar pregnancy which was managed by systemic methotrexate followed by dilation and curettage. The use of dilation and curettage was dictated by the persistence of gestational sac despite negativity of $\beta$-hCG levels. ${ }^{13}$ Some authors propose that dilation and curettage should not be the first line of management for scar pregnancy due to risk of perforation and catastrophic hemorrhage. ${ }^{14}$

Hysteroscopic removal of CSP was done by Chou et al after failure of systemic methotrexate treatment. ${ }^{15}$ However, it should not be forgotten that hysteroscopic approach requires clear visualization, excellent orientation of uterine cavity and also, an operator who is expert at manipulating hysteroscopic instruments. Hysteroscopic resection of scar pregnancy could be done only for the CSP that grows inwards towards the uterine cavity. There is risk of injury to urinary bladder during hysteroscopic resection if the anterior uterine wall is too thin.

If scar pregnancy grows towards the bladder and the abdominal cavity, a laparoscopic approach may be the better choice for removal of scar pregnancy. Laparoscopically assisted operative hysteroscopy has the added advantages of immediate detection of uterine and/or bladder perforation and rapid management of hemorrhage.

Shen et al, performed bilateral uterine artery chemoembolization with methotrexate for caesarean scar pregnancy in forty-six patients. They had administered methotrexate directly into the gestational foci through bilateral uterine arteries, which are its feeding vessels, with subsequent blockage of feeding vessels by occlusive agents that are injected through delivery catheters. Out of all, only one patient had to undergo emergency hysterectomy for excessive hemorrhage and rest were successfully treated. The risks of post-operative fever and abdominal pain, as well as longer duration of close monitoring and hospitalization should always be kept in mind in women treated with uterine artery embolization. ${ }^{16}$

Surgery has the advantage of offering the possibility of immediate remission. Huanxiao et al reported 40 cases of caesarean scar pregnancy, which were managed by transvaginal hysterotomy offering the advantage of decreased cost. Also, the complications of laparoscopy and hysteroscopy were avoided. ${ }^{17}$

Fortunately, our patient was successfully managed by mifepristone and systemic and intra-gestational sac methotrexate which was first used in our institute.

\section{CONCLUSION}

To conclude, the optimal management of caesarean scar pregnancy should be individualized depending upon the hemodynamic status, serum $\beta-\mathrm{hCG}$ levels, size of gestational sac, desire for preservation of future fertility, patient's compliance for long term follow-up and available infra-structure of the hospital. 
Funding: No funding sources

Conflict of interest: None declared

Ethical approval: Not required

\section{REFERENCES}

1. Rotas M, Habermen S, Levgur M. Caesarean scar ectopic pregnancies: etiology, diagnosis and management. Obstet Gynecol. 2006;107(6):1373-81.

2. Seow KM, Huang LW, Lin YH, Lin MY, Tsai YL, Hwang JL. Caesarean scar pregnancy: issues in management. Ultrasound Obstet Gynecol. 2004;23(3):247-53

3. Litwicka K, Greco E. Caesarean scar pregnancy: a review of management options. Curr Opin Obstet Gynecol. 2011;23(6):247-53.

4. Larsen JV, Solomon MH. Pregnancy in a uterine scar sacculus- an unusual cause of postabortal haemorrhage: a case report. S Afr Med J. 1978;53:142-3.

5. Miller DA, Chollet JA, Goodwin TM. Clinical risk factors for placenta previa-placenta accrete. Am J Obstet Gynecol. 1997;177:210-4.

6. Fait G, Goyert G, Sundareson A, Pickens A Jr. intramural pregnancy with foetal survival: case history and discussion of etiological factors. Obstet Gynecol. 1987;70(3 pt 2):472-4.

7. Jurkovic D, Hillaby K, Woelfer B, Lawrence A, Salim R, Elson CJ. First trimester diagnosis and management of pregnancies implanted into lower uterine segment caesarean section scar. Ultrasound Obstet Gynecol. 2003;21:220-7.

8. Godin PA, Bassil S, Donnez J. An ectopic pregnancy developing in a previous caesarean section scar. Fertil Steril. 1997;67:398-400.

9. Tritsch IE, Monteagudo A. Unforeseen consequences of the increasing rate of caesarean delieveries: placenta accreta and caesarean scar pregnancy-a review. Am J Obstet Gynecol. 2012;207:14-29.
10. Srinivas M, Raghupathy K, Ndumbe F. Dilemma in the management of caesarean scar pregnancy. Reprod Syst Sex Disord. 2014;3:1.

11. Shu S, Luo X, Wang Z, Yao Y. Cesarean scar pregnancy treated by curettage and aspiration guided by laparoscopy. Therap Clin Risk Manag. 2015:11.

12. Einenkel J, Stumpp P, Kosling S, Horn LC, Hockel M. A misdiagnosed case of cesarean scar pregnancy. Arch Gynecol Obstet. 2005;271:178-81.

13. Fadhlaoui A, Khrouf M, Khemiri K, Nouira K, Chaker A, Zhioua F. Successful conservative treatment of cesarean scar pregnancy with systemically administered methotrexate and subsequent dilatation and curettage: a case report. Case Reports Obstet Gynaecol. 2011;2012:248564:6.

14. Lee CL, Wang CJ, Chao A. Laparoscopic management of an ectopic pregnancy in a previous cesarean section scar. Hum Reprod. 1999;14(5):1234-6.

15. Chou YM, Wu D, Wu KY, Lee CL. Hysteroscopic removal of cesarean scar pregnancy after methotrexate treatment failure. Gynecol Minimal Invasive Ther. 2013;2:70-2.

16. Shen L, Tan A, Zhu H, Guo C, Liu D, Huang W. Bilateral uterine artery chemoembolization with methotrexate for cesarean scar pregnancy. Am J Obstet Gynecol. 2012;207:386:e1-6.

17. Huanxiao Z, Shuqin C, Hongye J, Hongzhe X, Gang $\mathrm{N}$, Chengkang $\mathrm{X}$, et al. Transvaginal Hysterotomy for cesarean scar pregnancy in 40 consecutive cases. Gynecol Surg. 2015;12:45-51.

Cite this article as: Rani V, Jain S, Malhotra V, Chauhan MB, Gautam S, Nanda S, et al. Caesarean scar pregnancy: a case report with review of management options. Int J Reprod Contracept Obstet Gynecol 2019;8:4602-5. 